\title{
Influence De La Fermentation Sur Les Caracteristiques Physicochimiques Et Sensorielles De La Farine Composite A Base De Banane Plantain Et D'amande De Cajou
}

\section{Ibrahim Fofana}

Laboratoire de Biochimie Sciences des Aliments, UFR Biosciences, Université Félix Houphouët Boigny de Cocody, Abidjan, Côte d'Ivoire

\section{Doudjo Soro}

UMRI Sciences des Procédés Alimentaires, chimiques et Environnementaux, Institut Nationale Polytechnique Félix Houphouët-Boigny (INP-HB), Yamoussoukro, Côte d'Ivoire.

\section{Mohamed Anderson Yeo}

UFR d'Ingénierie agronomique, Forestière et Environnementale, Université de Man, Côte d'Ivoire

\section{Ernest Kouadio Koffi}

Laboratoire de Biochimie Sciences des Aliments, UFR Biosciences, Université Félix Houphouët Boigny de Cocody, Abidjan, Côte d'Ivoire.

Doi: 10.19044/esj.2017.v13n30p395 URL:http://dx.doi.org/10.19044/esj.2017.v13n30p395

\begin{abstract}
The purpose of this study is to determine the effect of fermentation in the formulation of infant flour that meets the nutritional needs of children, using plantain and cashew kernel flours. For this purpose, cashew kernel flours (Anacardium occidentale L) fermented for $72 \mathrm{~h}$ and unfermented flour were incorporated into the plantain flour (Musa paradisiaca $\mathrm{sp}$ ) at different proportions $(0,10,15$ and 20\%). The biochemical, functional compositions and antinutrient levels of the formulations were determined. The results showed that the fermentation caused a more significant increase in the protein, lipid, energy and total phenolic content of the formulations in proportion to the incorporation rate. On the other hand, carbohydrate, fiber and ash levels were significantly reduced $(\mathrm{P}<0.05)$ as a result of the fermentation of cashew kernels compared with the incorporation of unfermented cashew flour. The study of the swelling powers and the solubility indices of the flours showed that the fermentation entails a significant decrease proportional to the level of cashew almond flour incorporated compared to those obtained with the unfermented flour. It was
\end{abstract}


also found that fermentation entailed a significant reduction $(\mathrm{P}<0.05)$ in the content of oxalic acid and tannins in cashew kernel flour. Sensory tests allowed limiting the maximum level of incorporation of fermented almond flour to $10 \%$ and that not fermented to $15 \%$.

Keywords: Musa paradisiaca, Anacardium occidentale, fermentation, infant flour, nutritional value, Côte d'Ivoire

\section{Resume}

L'objectif de cette étude est de déterminer l'effet de la fermentation dans la formulation d'une farine infantile répondant aux besoins nutritionnels des enfants, à partir de farines de banane plantain et d'amande de cajou. A cet effet, les farines d'amande de cajou (Anacardium occidentale $L$ ) fermentée pendant $72 \mathrm{~h}$ et celle non fermentée ont été incorporées à la farine de banane plantain (Musa paradisiaca $s p)$ à différentes proportions $(0$, 10,15 et $20 \%$ ). Les compositions biochimiques, fonctionnelles et les teneurs en antinutriments des formulations ont été déterminées. Les résultats ont montré que la fermentation provoque une augmentation plus significative de la teneur en protéine, en lipides, en énergie et la teneur phénolique totale des formulations proportionnellement au taux d'incorporation. Les teneurs en glucides, en fibres et en cendres ont par contre significativement $(\mathrm{P}<0,05)$ diminué suite à la fermentation de l'amande de cajou comparativement à l'incorporation de la farine de cajou non fermentée. L'étude des pouvoirs de gonflement et des indices de solubilité des farines ont montré que la fermentation entraine une diminution significative proportionnelle aux taux de farine d'amande de cajou incorporés comparée à ceux obtenues avec la farine non fermentée. On a également constaté que la fermentation entraînait une réduction significative $(\mathrm{P}<0,05)$ de la teneur en oxalates et en tanins dans la farine d'amande de cajou. Des tests sensoriels ont permis de limiter le niveau maximal d'incorporation de farine d'amande fermentée à $10 \%$ et celle non fermentée à $15 \%$.

Mots-Clefs:Musa paradisiaca, Anacardium occidentale, fermentation, farine infantile, valeur nutritive, Côte d'Ivoire

\section{Introduction}

La banane plantain est une excellente source d'hydrate de carbone, mais sa qualité nutritionnelle est relativement faible car elle manque de protéines et de lipides (Bonnet-Bruno, 2012). En raison de l'importance alimentaire de la banane plantain, des efforts considérables sont déployés pour améliorer sa valeur nutritive. L'insuffisance de protéine dans l'alimentation et particulièrement dans les pays en voie de développement, a 
dicté la recherche de nouvelles sources de protéine pour substituer ou pour compléter les sources existantes dans la formulation des farines infantiles. En 2015, avec une production de 702510 tonnes, la Côte d'Ivoire occupe le premier rang mondial de producteur de noix de cajou brut avec $25 \%$ de la part de marché mondial (CCA, 2016). Il est bien documenté que les noix de cajou contiennent des nutriments essentiels comme les protéines, les graisses et des quantités appréciables de minéraux (Akinhanmi et al, 2008). Les noix de cajou sont une bonne source de protéines (20-24g / $100 \mathrm{~g})$, de glucides $(23-25 \mathrm{~g} / 100 \mathrm{~g})$ et de matières grasses $(40-57 \mathrm{~g} / 100 \mathrm{~g})$ (Nascimento et al., 2010; Yang, 2009). Malgré les avantages nutritionnels de la noix de cajou, son utilisation comme nourriture est limitée aux collations (Ijarotimi et al, 2012). L'acceptabilité et l'utilisation optimale d'une partie de noix de cajou sont limitées par la présence de facteurs antinutritionnels tels que les tanins, l'acide phytique, les inhibiteurs d'amylase et des inhibiteurs de la trypsine. Heureusement, certaines techniques de traitement peuvent réduire ou détruire les antinutriments présents. La fermentation est une méthode peu coûteuse et simple pour améliorer la valeur nutritive des aliments de base et réduire leurs facteurs antinutritionnels (Mbugua, 1988). De nombreux travaux ont prouvé que la fermentation pouvait être efficacement utilisée pour améliorer la qualité nutritionnelle des grains de céréales en augmentant la teneur en protéines et la digestibilité (Inyang et Zakari, 2008 ; Ali et al., 2003 ; El Hag et al., 2002). De nombreux chercheurs ont également constaté que la fermentation diminue l'activité inhibitrice de la trypsine (TIA), l'inhibiteur de l'amylase, l'acidité, l'acide phytique et les tanins (Osman, 2004 ; Ejigui et al., 2005 ; Eltayeb et al., 2007 ; Abdel-Haleem et al., 2008 ). En raison des conséquences bénéfiques de la fermentation sur l'amélioration de la qualité nutritionnelle et sanitaire de ces aliments, la FAO et l'UNICEF sont enclins à encourager et à soutenir l'utilisation des aliments traditionnels amylacés fermentes dans l'alimentation complémentaire du jeune enfant.

$\mathrm{Eu}$ égard à tous ces avantages, il nous est apparu important d'évaluer l'influence de la fermentation sur les caractéristiques physicochimiques et sensorielles de la farine composite à base de banane plantain et d'amande de cajou afin de formuler des aliments complémentaires à haute valeur nutritive.

\section{Matériel et méthodes}

\section{Matériel biologique}

Le matériel végétal de l'étude est constitué de farines produites à base de bananes plantain tournant, fraîche et intactes, cultivar Corne 1 (Figure 1).

Les bananes ont été sélectionnées et achetées chez des grossistes au marché du quartier Moh faitai dans la ville de Yamoussoukro, capitale 
politique de la Côte d'Ivoire, région des lacs, située entre la zone forestière et la zone savanicole

Les noix de cajou (Anacardium Occidentale L) utilisées pour l'enrichissement sont collectées au sein de l'atelier de génie mécanique de l'Institut Nationale Polytechnique Félix Houphouët Boigny (INP/HB), Yamoussoukro, Côte d'Ivoire (Figure 2).

Deux farines infantiles de commerce sont utilisées comme référence. BLEDINE constitué d'un mélange banane / lait, produite par Blédina SAS et FARINOR produite par le laboratoire Nutribon

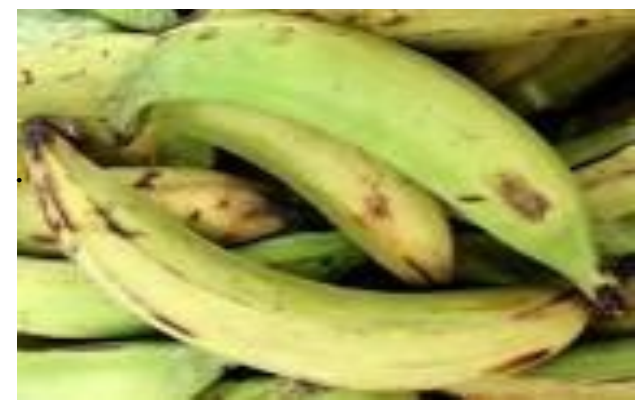

Figure 1 : Banane plantain tournant, cultivar Corne 1 (Anacardium Occidentale L)

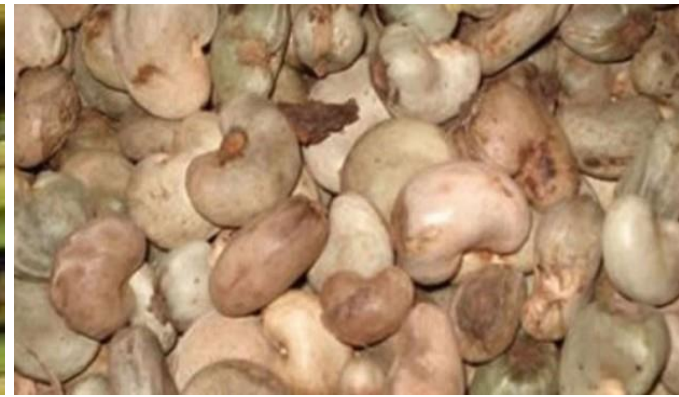

Figure2 : Noix de cajou c

\section{Méthodes}

\section{Production des farines}

\section{La farine de banane plantain}

La farine de banane plantain est produite selon le procédé de PérezSira E (1997) avec peu de modifications pour la prévention du brunissement enzymatique. Les bananes, fraîches et matures sont lavées et cuites dans une cocotte-minute à une température comprise entre 98 et $100^{\circ} \mathrm{C}$ pendant 15 minutes jusqu'à tendreté. Les bananes précuites sont ensuite pelées puis découpées en cossettes à une épaisseur moyenne de $1 \mathrm{~cm}$ en utilisant un couteau Les cossettes sont séchées à l'air dans des armoires (BR185H, Gallenkamp, Yorkshire, Royaume-Uni) du four à une température de $65^{\circ} \mathrm{C}$ pendant 24 heures. Les cossettes séchées sont enfin broyées dans un broyeur à marteaux pour obtenir de la farine précuite de banane plantain.

\section{Les farines d'amande de cajou}

\section{Le traitement des noix de cajou}

Le traitement des noix de cajou a été inspiré du procédé Falade et al ., 2004 modifié. Un lot de noix de cajou triées et calibrées est cuit dans un cuiseur à vapeur à $115^{\circ} \mathrm{C}$ pendant $45 \mathrm{~min}$, puis laissé sécher à température ambiante pendant $48 \mathrm{~h}$. Les noix de cajou séchées sont décortiquées manuellement en deux moitiés égales à l'aide d'un décortiqueur à commande 
manuelle. Les amandes sont ensuite séparées des coquilles à l'aide de petits couteaux et séchées à l'air dans des armoires (BR185H, Gallenkamp, Yorkshire, Royaume-Uni) du four à une température de $85^{\circ} \mathrm{C}$ pendant 2 heures puis dépelliculées. Les amandes sont séchées au four à $65{ }^{\circ} \mathrm{C}$ pendant 24 heures pour que l'humidité soit comprise entre 5 et $6 \%$.

\section{Production de la farine d'amande de cajou non fermentée}

La farine d'amande de cajou produite, a été inspirée par la méthode décrite par Sze-Tao et Sathe., 2004 modifiée. Ainsi, les amandes de cajou précédemment traitées sont concassées à l'aide d'un broyeur semi-artisanal. L'huile des amandes a été ensuite extraite avec du n-hexane deux fois de suite au rapport de 1:1 ( $\mathrm{p} / \mathrm{p}$ ), dans une cuve en inox par macération continue pendant 30 minutes. La cuve hermétiquement fermée est portée à ébullition pendant 50 minutes sur une plaque chauffante à $130^{\circ} \mathrm{C}$. Après 24 heures d'incubation, le surnageant contenant l'huile et l'hexane est retiré, les tourteaux sont collectés dans un tissu blanc en coton et mis sous presse pendant 24 heures. Les tourteaux dégraissés sont ensuite étalés sur un plateau inoxydable et mis à l'étuve à $70^{\circ} \mathrm{C}$ pendant 12 heures à sécher afin d'éliminer les traces de solvant. Les tourteaux sont enfin broyés pour obtenir la farine de granulométrie $150 \mu \mathrm{m}$, puis emballés dans des sachets en plastique polyéthylène et conservés.

\section{Production de la farine d'amande de cajou fermentée}

Pour produire la farine à partir de tourteaux d'amande de cajou, la méthode de Ijarotimi et al., 2012 modifiée a été utilisée. Les amandes obtenues sont bouillies à $100^{\circ} \mathrm{C}$ pendant $1 \mathrm{~h}$. Les amandes bouillies sont étroitement enveloppées dans la feuille de plantain pendant 72 heures pour la fermentation. La fermentation est effectuée en utilisant les micro-organismes naturellement présents sur la surface des feuilles de plantain. Les amandes fermentées sont séchées au four à $65^{\circ} \mathrm{C}$ pendant 48 heures. Les amandes fermentées sont concassées puis l'hexane est ajouté comme décrit ci-dessus pour l'extraction d'huile. Après l'extraction, les tourteaux sont séchés à $70^{\circ} \mathrm{C}$ pendant $12 \mathrm{~h}$ pour l'évaporation de l'hexane. Les tourteaux sont broyés dans un broyeur et conditionnés dans des sachets en polyéthylène.

\section{Formulation des farines infantiles : plantain / amande de cajou}

Les farines composites plantain et amande de cajou ont été obtenues par l'incorporation de proportions respectives de $0,10,15$ et 20\% de farine d'anacarde dans respectivement $100,90,85$ et $80 \%$ de farine de plantain. Chaque formulation est soigneusement mélangée dans un mixeur, ensuite répartie en fractions de $250 \mathrm{~g}$ dans des sachets plastiques en polyéthylène, puis stockée pour les analyses. 


\section{Composition physico-chimiques}

Le taux d'humidité est déterminé par séchage des échantillons dans une étuve (Memmert 854 Schwabach, Allemagne) à $105^{\circ} \mathrm{C}$ pendant 24 heures [18]. Le pourcentage de protéine brute est déterminé en utilisant la méthode de Kjeldahl avec l'unité Kjeltec 8400 de l'analyseur (FOSS, Suède) et l'atome d'azote en pourcentage $(\% \mathrm{~N})$ obtenu est utilisé pour calculer le pourcentage de protéine brute $(\% \mathrm{P})$ en utilisant la relation: $\% \mathrm{P}=\% \mathrm{~N}$ x 6.25 (AOAC, 1995). La teneur en lipide est déterminée en utilisant l'extraction par l'hexane dans un extracteur de type Soxhlet (Unid Tecator, System HT2 1045, Suède). Après évaporation du solvant et séchage de la capsule à l'étuve (Memmert $854 \mathrm{Schwabach}$, Allemagne) à $105^{\circ} \mathrm{C}$ pendant $30 \mathrm{~min}$; la différence de poids a donné la teneur en lipides de l'échantillon (AOAC, 1995). Le pourcentage de cendres (\%) est déterminé en incinérant des échantillons dans un four à moufle (Nabertherm GmbH Babnhofstr. 20, 28865 Lilienthal/Bremen, Germany) à $600^{\circ} \mathrm{C}$ pendant 6 heures. La cendre est refroidie dans un dessiccateur et pesée (AOAC, 1995). Pour les fibres brutes, $1 \mathrm{~g}$ d'échantillon de farine séchée est digéré avec de l'acide sulfurique 1,25 $\mathrm{N}$ et une solution d'hydroxyde de sodium 1,25 N. Le résidu insoluble obtenu est lavé à l'eau chaude et séché dans une étuve (Memmert 854 Schwabach, Allemagne) à $105^{\circ} \mathrm{C}$ pendant 24 heures. Le résidu séché est ensuite incinéré au four (Nabertherm GmbH Babnhofstr. 20, 28865 Lilienthal/Bremen, Germany) à $600^{\circ} \mathrm{C}$ pendant 6 heures et pesé pour la détermination de la teneur en fibres brutes. Les glucides et la valeur énergétique sont calculés en utilisant les formules suivantes (AOAC, 1995). de cendres)

Glucides : 100 - (\% d'humidité $+\%$ de protéines $+\%$ de lipides $+\%$

Valeur énergétique : $(\%$ de protéines $\mathrm{x} 4)+(\%$ d'hydrates de carbone $\mathrm{x} 4)+(\%$ de lipides $\mathrm{x} 9)$

\section{Propriétés fonctionnelles}

Le $\mathrm{pH}$ de tous les échantillons a été déterminé en utilisant la méthode (AOAC, 1995).

Dix (10) grammes de farine ont été délayés dans $100 \mathrm{ml}$ d'eau distillée. L'ensemble est macéré pendant $30 \mathrm{~min}$. Le mélange obtenu est centrifugé à $3500 \mathrm{rpm}$ pendant $30 \mathrm{~min}$ à l'aide d'une centrifugeuse (TAI SHI LI XIN JI TDL-4, en Chine). Le pH est déterminé selon la méthode potentiométrique en utilisant l'électrode d'un compteur pH (HI1230 PH 13). Dix millilitres $(10 \mathrm{~mL})$ du surnageant précédemment obtenu est prélevé et le $\mathrm{pH}$ est mesuré au moyen d'un pH-mètre (HANNA INSTRUMENTS HI8424). La valeur du $\mathrm{pH}$ est lue directement sur l'écran du pH-mètre.

La capacité de gonflement et l'indice de solubilité à l'eau des farines sont déterminés par gravimétrie (Li et Corke., 1999). Une suspension de 
farine $(0,3 \mathrm{~g}+15 \mathrm{~mL}$ d'eau distillée $)$ est chauffée de $50{ }^{\circ} \mathrm{C}$ à $95{ }^{\circ} \mathrm{C}$, puis maintenue à $95{ }^{\circ} \mathrm{C}$ pendant 15 min sous agitation maximale et centrifugée à $2800 \mathrm{rpm}$ à l'aide d'une centrifugeuse (TAI SHI LI XIN JI TDL-4, en Chine). Le surnageant est prélevé et séché à $105^{\circ} \mathrm{C}$ pendant $24 \mathrm{~h}$ puis le résidu est pesé. Le pourcentage de farine dissous dans l'eau détermine la solubilité (S) :

$$
\mathrm{S}(\%)=(\mathrm{E} \times 100) / \mathrm{m}
$$
prélevé

$\mathrm{E}=$ masse du surnageant après étuvage et $\mathrm{m}=$ masse de l'échantillon

Le culot est immédiatement pesé, séché à l'étuve (MEMMERT UM 500, MEMMERT Gmbh+Co.KG, Allemagne-Schwabach) à $105^{\circ} \mathrm{C}$ pendant 24 h et repesé. Le pouvoir de gonflement $(\mathrm{G})$ est déterminé selon la formule: $\mathrm{G}(\mathrm{ge} / \mathrm{gMS})=(\mathrm{mh}-\mathrm{ms}) / \mathrm{ms}$ $\mathrm{mh}=$ masse du culot humide $(\mathrm{g})$ $\mathrm{ms}=$ masse du culot séché à l'étuve $(\mathrm{g})$.

\section{Détermination des teneurs en polyphénols totaux et facteurs antinutritionnels}

Les phénols totaux sont extraits selon la Méthode AOAC (Christensen, 1974) utilisant le réactif de Folin Ciocalteu. Pour l'extraction ,1 g de farine est placé dans un bécher dans lequel sont ajoutés $100 \mathrm{ml}$ d'acide oxalique à $0,3 \%(\mathrm{~g} / \mathrm{v})$. Le mélange est agité à l'aide d'un agitateur magnétique pendant $30 \mathrm{~min}$. l'ensemble est centrifugé à 3000trs pendant 15 minutes. Ensuite l'extrait est filtré sur du papier Whatman $n^{\circ} 41$. Pour le dosage, $1 \mathrm{ml}$ de l'extrait diluée dans $8 \mathrm{ml}$ d'eau distillée est ajouté dans un tube, plus $0,5 \mathrm{ml}$ de réactif de Folin Ciocalteu dilué $(1 / 10)$, et $1,5 \mathrm{ml}$ de solution de carbonate de sodium (7.5\%). Le mélange est laissé à l'obscurité pendant 1 heure à température ambiante. La lecture est faite à une absorption de $765 \mathrm{~nm}$ au spectrophotomètre. Une gamme étalon est réalisée avec l'acide gallique à différentes concentrations $(0$ à $1 \mathrm{mg} / \mathrm{ml})$. La teneur en composés phénoliques de chaque échantillon est ensuite calculée à partir de la courbe d'étalonnage et exprimée en g d'équivalent d'acide gallique pour $100 \mathrm{~g}$ de matières sèches.

Le dosage des tannins est effectué suivant la méthode décrite par Ba et al.,2010). Un (1) $\mathrm{mL}$ d'extrait méthanolique est introduit dans un tube à essai. Au contenu du tube sont ajoutés $5 \mathrm{~mL}$ de réactif à la vanilline à $1 \%$ $(\mathrm{p} / \mathrm{v})$. Le tube est laissé au repos pendant 30 min à l'obscurité et la densité optique (DO) est lue à $500 \mathrm{~nm}$ contre un blanc. La quantité de tannins des échantillons est déterminée à l'aide d'une gamme étalon établie à partir d'une solution mère d'acide tannique $(2 \mathrm{mg} / \mathrm{mL})$ réalisée dans les mêmes conditions que l'essai. 
Le dosage des oxalates est réalisé selon la méthode décrite par Day et Underwood (1986) utilisant le permanganate de potassium. Un (1) gramme d'échantillon séché à l'étuve et broyé est homogénéisé dans $75 \mathrm{~mL}$ d'acide sulfurique $3 \mathrm{M}$. Le mélange est porté sous agitation magnétique pendant $1 \mathrm{~h}$ puis filtré. Vingt cinq (25) millilitres de filtrat sont titrés à chaud avec une solution de permanganate de potassium à $0,05 \mathrm{M}$ jusqu'au virage au rose persistant.

\section{Analyses sensorielles \\ Préparation des bouillies}

Des essais préliminaires avec des dégustateurs (non entrainés) ont permis de retenir la cuisson de $50 \mathrm{~g}$ de farine dans $250 \mathrm{ml}$ d'eau de robinet. Cette quantité a tenu compte de la fluidité de la bouillie. La cuisson a duré 7 minutes sur feu doux et du sucre de table a été ajouté au taux de $6 \%$ en fin de cuisson. Les bouillies ont été mises à refroidir à la température ambiante dans la salle de préparation jusqu'à $50^{\circ} \mathrm{C}$ environ avant d'être servies.

\section{Test d'acceptabilité}

Le panel est constitué de 60 personnes non entraînées (jeunes filles et garçons, femmes et hommes adultes), recrutées sur la base de leur disponibilité. Les échantillons de bouillies codés (avec 3 chiffres) sont présentés simultanément à chaque panéliste dans un ordre randomisé. Le plaisir perçu par chaque panéliste est marqué sur une échelle hédonique à 9 points. Les notes allant de 9 (extrêmement plaisant) à 1 (extrêmement déplaisant) sont affectées aux différentes modalités de l'échelle (Meilgaard et al., 1999).

\section{Test descriptif quantitatif}

La méthode consiste à évaluer et quantifier les descripteurs appropriés (odeur, goût, consistance, couleur et la texture) selon une échelle de catégorie. Les bouillies préparées à base des farines de banane plantain enrichies ou non à 10,15 et $20 \%$ de farine d'anacarde ainsi que celles des farines infantiles de commerce BLEDINE et FARINOR sont présentées à un jury de 10 personnes recrutées et initiées à la méthodologie d'analyse. Ces bouillies sont codées (avec 3 chiffres) et présentées simultanément dans un ordre randomisé (Meilgaard et al., 1999.

\section{Analyses statistiques des données}

L'analyse statistique est réalisée par le logiciel « Statistical Program for Social Sciences »version 7.1. La variabilité des paramètres étudiés a été testée selon le taux d'enrichissement. Une analyse de variance (ANOVA) a été effectuée et la significativité des différences entre les échantillons de farines est déterminée au risque d'erreur $\alpha=0,05$ selon le test de Duncan. 


\section{Résultats}

\section{Caractéristiques physico-chimiques des farines}

Les résultats du Tableau 1 rendent compte de la composition physicochimique des différentes formulations de farines.

La fortification à l'amande de cajou entraine une augmentation proportionnellement au taux d'incorporation des teneurs en protéines et lipides de la farine banane plantain. Les effets les plus significatifs $(P<0,05)$ de ces paramètres sont observés au niveau des échantillons fermentés. Ainsi, pour la farine de banane plantain, une incorporation de $20 \%$ de farine d'anacarde fermentée, augmente les teneurs respectives en protéines et en lipides de $3,33 \pm 0,02 \mathrm{~g} / 100 \mathrm{~g}$ et $0,59 \pm 0,05 \mathrm{~g} / 100 \mathrm{~g}$ à respectivement $10,19 \pm 0,69 \mathrm{~g} / 100 \mathrm{~g}$ et $6,74 \pm 0,48 \mathrm{~g} / 100 \mathrm{~g}$. Quant aux farines à base de farine d'anacarde non fermentée, ces valeurs passent respectivement à $9,33 \pm 0,05 \mathrm{~g} / 100 \mathrm{~g}$ et $6,39 \pm 0,04 \mathrm{~g} / 100 \mathrm{~g}$.

A la différence des protéines et des lipides, la fortification entraine une diminution significative $(\mathrm{P}<0,05)$ de la teneur en glucides totaux dans la farine de banane plantain. Toutefois les formulations contenant la farine d'amande de cajou fermentée présentent une diminution plus significative. Ainsi ces teneurs passent respectivement entre 87,63 $\pm 0,97 \mathrm{~g} / 100 \mathrm{~g}$ à $76,23 \pm 0,33 \mathrm{~g} / 100 \mathrm{~g}$ pour les formulations fermentées et de $87,63 \pm 0,97 \mathrm{~g}$ $/ 100 \mathrm{~g}$ à $77,33 \pm 0,07 \mathrm{~g} / 100 \mathrm{~g}$ pour celles contenant la farine d'anacarde non fermentée. Les teneurs en fibres ont suivi la même tendance que les glucides totaux lors de la fermentation de l'anacarde. Ces teneurs passent de 4,97 $\pm 0,01 \mathrm{~g} / 100 \mathrm{~g}$ dans la farine d'amande de cajou non fermentée (FCNF) à $2,72 \pm 1,08 \mathrm{~g} / 100 \mathrm{~g}$ dans celle fermentée (FCF). Cette diminution significative de la teneur en fibres dans la farine fermentée s'est traduite par une faible augmentation lors de fortification $(0,59 \pm 0,02 \mathrm{~g} / 100 \mathrm{~g}$ à $1,25 \pm 0,30 \mathrm{~g} / 100 \mathrm{~g}$ ) comparativement aux formulations non fermentées $(0,59 \pm 0,02 \mathrm{~g} / 100 \mathrm{~g}$ à $1,55 \pm 0,1 \mathrm{~g} / 100 \mathrm{~g})$.

La fermentation a aussi entrainé une diminution de la teneur en cendre de la farine d'amande de cajou. Le taux de cendre passe de 3,66 $\pm 1,15$ $\mathrm{g} / 100 \mathrm{~g}$ dans la farine non fermentée à $3,00 \pm 0,37 \mathrm{~g} / 100 \mathrm{~g}$ dans la farine fermentée. Toutefois la fortification de la farine de banane plantain aux farines d'amandes de cajou entraine une augmentation proportionnellement au taux d'incorporation des farines d'amandes de cajou. Les teneurs oscillent respectivement de $2,00 \pm 1 \mathrm{~g} / 100 \mathrm{~g}$ à $2,27 \pm 0,01 \mathrm{~g} / 100 \mathrm{~g}$ dans les formulations non fermentées et de $2,00 \pm 1 \mathrm{~g} / 100 \mathrm{~g}$ à $2,17 \pm 1,07 \mathrm{~g} / 100 \mathrm{~g}$ dans les formulations fermentées.

Quant au taux d'humidité des différentes formulations, il a très peu varié. L'humidité des farines oscille entre 5,66 $\pm 0,08 \%$ et 4,70 $\pm 0,08 \%$. 
Tableau 1 : Composition chimique de farines composites à base de banane plantain et d'amande de cajou

\begin{tabular}{|c|c|c|c|c|c|c|}
\hline \multicolumn{7}{|c|}{ Paramètres (\%) } \\
\hline $\begin{array}{c}\text { Formulatio } \\
n s\end{array}$ & Humidité & Protéines & Lipides & Glucides & Fibres & Cendres \\
\hline FB & $\begin{array}{c}6,43 \pm 0,0 \\
5^{\mathrm{a}}\end{array}$ & $3,33 \pm 0,02^{\mathrm{i}}$ & $0,59 \pm 0,05^{\mathrm{j}}$ & $\begin{array}{c}87,63 \pm 0,9 \\
7^{\mathrm{a}}\end{array}$ & $\begin{array}{c}0,59 \pm 0,0 \\
2^{\mathrm{i}}\end{array}$ & $2,00 \pm 1^{b}$ \\
\hline FCNF & $\begin{array}{c}3,06 \pm 0,2 \\
3^{\mathrm{f}} \\
\end{array}$ & $24,18 \pm 0,5^{\mathrm{b}}$ & $\begin{array}{c}29,25 \pm 0,0 \\
2^{\mathrm{b}} \\
\end{array}$ & $\begin{array}{c}39,83 \pm 0,9 \\
0^{\mathrm{h}} \\
\end{array}$ & $\begin{array}{c}4,97 \pm 0,0 \\
1^{\mathrm{a}} \\
\end{array}$ & $\begin{array}{c}3,66 \pm 1,15 \\
\text { a }\end{array}$ \\
\hline FCF & $\begin{array}{c}4,56 \pm 0,1 \\
5^{\mathrm{d}} \\
\end{array}$ & $32,38 \pm 0,2^{\mathrm{a}}$ & $\begin{array}{c}31,05 \pm 0,0 \\
2^{\mathrm{a}} \\
\end{array}$ & $\begin{array}{c}28,96 \pm 0,9 \\
8^{\mathrm{i}} \\
\end{array}$ & $\begin{array}{c}2,72 \pm 1,0 \\
8^{\mathrm{b}} \\
\end{array}$ & $\begin{array}{c}3,00 \pm 0,37 \\
\text { ab }\end{array}$ \\
\hline FB10FCNF & $5,70 \pm 0,1^{b}$ & $7,15 \pm 0,02^{\mathrm{h}}$ & $2,92 \pm 0,01^{\mathrm{i}}$ & $\begin{array}{c}82,13 \pm 0,0 \\
9^{\mathrm{b}} \\
\end{array}$ & $\begin{array}{c}1,22 \pm 0,1 \\
1^{\mathrm{e}}\end{array}$ & $\begin{array}{c}2,08 \pm 0,01 \\
\mathrm{~b}\end{array}$ \\
\hline FB15FCNF & $\begin{array}{c}5,26 \pm 0,0 \\
5^{\mathrm{c}}\end{array}$ & $8,03 \pm 0,03^{\mathrm{g}}$ & $4,92 \pm 0,02^{\mathrm{g}}$ & $\begin{array}{c}79,62 \pm 0,0 \\
4^{\text {c }}\end{array}$ & $\begin{array}{c}1,40 \pm 0,0 \\
3^{\mathrm{d}}\end{array}$ & $\begin{array}{c}2,15 \pm 0,01 \\
\mathrm{~b}\end{array}$ \\
\hline FB20FCNF & $\begin{array}{c}4,70 \pm 0,0 \\
5^{\mathrm{d}}\end{array}$ & $9,33 \pm 0,05^{\mathrm{e}}$ & $6,39 \pm 0,04^{\mathrm{d}}$ & $\begin{array}{c}77,33 \pm 0,0 \\
7^{\mathrm{e}}\end{array}$ & $1,55 \pm 0,2^{\mathrm{c}}$ & $\begin{array}{c}2,27 \pm 0,01 \\
\text { b }\end{array}$ \\
\hline FB10FCF & $\begin{array}{c}5,66 \pm 0,1 \\
1^{\mathrm{b}}\end{array}$ & $8,75 \pm 0,22^{\mathrm{f}}$ & $3,69 \pm 0,29^{\mathrm{h}}$ & $\begin{array}{c}79,85 \pm 0,1 \\
2^{\mathrm{c}}\end{array}$ & $\begin{array}{c}0,84 \pm 0,6 \\
4^{\mathrm{g}}\end{array}$ & $\begin{array}{c}2,04 \pm 0,23 \\
\text { b }\end{array}$ \\
\hline FB15FCF & $\begin{array}{c}5,13 \pm 0,1 \\
5^{\mathrm{c}}\end{array}$ & $9,41 \pm 0,17^{\mathrm{e}}$ & $5,01 \pm 0,83^{\mathrm{f}}$ & $\begin{array}{c}78,33 \pm 0,1 \\
1^{\mathrm{d}}\end{array}$ & $\begin{array}{c}1,08 \pm 0,1 \\
6^{\mathrm{f}}\end{array}$ & $\begin{array}{c}2,10 \pm 0,85 \\
\text { b }\end{array}$ \\
\hline FB20FCF & $\begin{array}{c}4,60 \pm 0,1 \\
3^{\mathrm{d}}\end{array}$ & $\begin{array}{c}10,19 \pm 0,6 \\
7^{\mathrm{d}}\end{array}$ & $6,74 \pm 0,48^{c}$ & $\begin{array}{c}76,23 \pm 0,3 \\
5^{\mathrm{f}}\end{array}$ & $1,25 \pm 0,3^{\mathrm{e}}$ & $\begin{array}{c}2,17 \pm 1,07 \\
\mathrm{~b}\end{array}$ \\
\hline BLEDINE & $\begin{array}{c}4,16 \pm 0,0 \\
5^{\mathrm{e}}\end{array}$ & $\begin{array}{c}13,69 \pm 0,0 \\
5^{\mathrm{c}}\end{array}$ & $6,01 \pm 0,02^{\mathrm{e}}$ & $\begin{array}{c}72,81 \pm 0,2 \\
8^{\mathrm{g}}\end{array}$ & $2,29 \pm 0,0^{\mathrm{h}}$ & $\begin{array}{c}3,33 \pm 0,57 \\
\text { a }\end{array}$ \\
\hline
\end{tabular}

Toutes ces valeurs sont les moyennes de trois déterminations. Les notes de la même colonne portant en exposant des lettres différentes sont statistiquement différentes à $\mathrm{P} \leq 0,05$.

$\mathbf{F B}=$ Farine de banane plantain $; \mathbf{F C N F}=$ Farine d'anacarde non fermentée ; $\mathbf{F C F}=$ Farine d'anacarde fermenté $; \mathbf{F B 1 0 F C N F}=$ Farine de banane plantain enrichie à $10 \%$ d'anacarde non fermentée $\mathbf{F B 1 0 F C F}=$ Farine de banane plantain enrichie à 10\% d'anacarde fermentée ; FB15FCNF $=$ Farine de banane plantain enrichie à $15 \%$ d'anacarde non fermentée ; FB15FCF= Farine de banane plantain enrichie à $15 \%$ d'anacarde fermentée FB20FCNF = Farine de banane plantain enrichie à 20\% d'anacarde non fermentée $; \mathbf{F B 2 0 F C F}=$ Farine de banane plantain enrichie à $20 \%$ d'anacarde fermentée $\quad$ BLEDINE $=$ Farine infantile témoin du commerce

\section{Propriétés fonctionnelles}

Les caractéristiques fonctionnelles des farines sont présentées dans le tableau 2. La présente étude a prouvé que l'enrichissement de la farine de banane à la farine d'anacarde fermentée entraine une diminution significativement proportionnelle au taux d'incorporation d'anacarde, le pouvoir de gonflement des farines de plantain $(8,78 \pm 0,01$ ge/gMS à 
7,82 $\pm 0,44 \mathrm{ge} / \mathrm{gMS})$ comparativement à celle contenant la farine d'anacarde non fermentée $(8,78 \pm 0,01 \mathrm{ge} / \mathrm{gMS}$ à $8,06 \pm 0,01 \mathrm{ge} / \mathrm{gMS})$. Quant aux valeurs de l'indice de solubilité dans l'eau, ils ont suivi la même tendance que la capacité de gonflement. Ces valeurs sont comprises entre 20,33 $\pm 1,54 \%$ et $13,10 \pm 0,38 \%$ pour les farines contenant la farine d'amande de cajou fermentée et $20,33 \pm 1,54 \%$ et $14,66 \pm 0,57 \%$ pour celles contenant la farine d'amande de cajou non fermentée. Malgré la diminution significative des capacités de gonflement des farines formulées elles sont restées supérieures à celles de la farine témoin $(4,34 \pm 0,15 \%)$.

La fermentation entraine une diminution significative du $\mathrm{pH}$ proportionnelle au taux d'incorporation comparativement à celles fortifiées à la farine d'amande de cajou non fermentée.

Une augmentation de la valeur énergétique est observée au fur et mesure que le taux de substitution à l'anacarde augmente. Les formulations fermentées présentent des valeurs légèrement plus élevées. Les valeurs en énergie métabolisable des farines oscillent respectivement entre $369,23 \pm 1,77$ et $404,22 \pm 0,52 \mathrm{kcal} / 100 \mathrm{~g}$ pour les formulations non fermentées et $369,23 \pm 1,77$ et $406,40 \pm 0,41 \mathrm{kcal} / 100 \mathrm{~g}$ des formulations fermentées et celle de la farine témoin de commerce (BLEDINE) est de 400,09 $\pm 1,44 \mathrm{kcal} / 100 \mathrm{~g}$.

Tableau 2 : Propriétés fonctionnelles des farines composites à base de banane plantain et d'amande de cajou

\begin{tabular}{|c|c|c|c|c|}
\hline \multicolumn{5}{|c|}{ Paramètres } \\
\hline Formulations & $\mathrm{pH}$ & $\begin{array}{c}\text { Energie } \\
(\mathrm{kcal} / 100 \mathrm{~g})\end{array}$ & $\begin{array}{c}\text { Gonflement } \\
(\mathrm{ge} / \mathrm{gMS})\end{array}$ & $\begin{array}{c}\text { Solubilité } \\
(\%)\end{array}$ \\
\hline FB & $5,39 \pm 0,11^{\mathrm{f}}$ & $369,23 \pm 1,77^{\mathrm{h}}$ & $8,78 \pm 0,98^{\mathrm{a}}$ & $20,33 \pm 1,54^{\mathrm{b}}$ \\
\hline FCNF & $6,15 \pm 0,05^{\mathrm{b}}$ & $519,33 \pm 1,79^{\mathrm{b}}$ & - & - \\
\hline FCF & $5,56 \pm 0,01^{\mathrm{c}}$ & $524,83 \pm 0,71^{\mathrm{a}}$ & - & - \\
\hline FB10FCNF & $5,46 \pm 0,05^{\mathrm{e}}$ & $383,47 \pm 0,51^{\mathrm{f}}$ & $8,26 \pm 1,15^{\mathrm{b}}$ & $18,39 \pm 1,73^{\mathrm{c}}$ \\
\hline FB15FCNF & $5,50 \pm 0,05^{\mathrm{d}}$ & $394,92 \pm 0,40^{\mathrm{d}}$ & $8,11 \pm 0,56^{\mathrm{c}}$ & $16,66 \pm 0,57^{\mathrm{d}}$ \\
\hline FB20FCNF & $5,57 \pm 0,01^{\mathrm{c}}$ & $404,22 \pm 0,52^{\mathrm{c}}$ & $8,06 \pm 1,07^{\mathrm{d}}$ & $14,66 \pm 0,57^{\mathrm{f}}$ \\
\hline FB10FCF & $5,31 \pm 0,17^{\mathrm{i}}$ & $387,63 \pm 0,51^{\mathrm{e}}$ & $8,04 \pm 0,35^{\mathrm{d}}$ & $15,71 \pm 0,49^{\mathrm{e}}$ \\
\hline FB15FCF & $5,34 \pm 0,01^{\mathrm{h}}$ & $396,12 \pm 0,66^{\mathrm{d}}$ & $7,94 \pm 0,26^{\mathrm{e}}$ & $14,21 \pm 1,08^{\mathrm{g}}$ \\
\hline FB20FCF & $5,37 \pm 0,01^{\mathrm{g}}$ & $406,40 \pm 0,41^{\mathrm{c}}$ & $7,82 \pm 0,44^{\mathrm{f}}$ & $13,10 \pm 0,38^{\mathrm{h}}$ \\
\hline BLEDINE & $6,24 \pm 0,1^{\mathrm{a}}$ & $400,09 \pm 1,44^{\mathrm{c}}$ & $4,34 \pm 0,15^{\mathrm{g}}$ & $33,33 \pm 0,15^{\mathrm{a}}$ \\
\hline
\end{tabular}

Toutes ces valeurs sont les moyennes de trois déterminations. Les notes de la même colonne portant en exposant des lettres différentes sont statistiquement différentes à $\mathrm{P} \leq 0,05$.

$\mathbf{F B}=$ Farine de banane plantain $; \mathbf{F C N F}=$ Farine d'anacarde non fermentée ; $\mathbf{F C F}=$ Farine d'anacarde fermenté $; \mathbf{F B 1 0 F C N F}=$ Farine de banane plantain enrichie à 10\% d'anacarde non fermentée ; FB10FCF= Farine de banane plantain enrichie à $10 \%$ d'anacarde fermentée; FB15FCNF $=$ Farine de banane plantain enrichie à $15 \%$ d'anacarde non fermentée ; FB15FCF= 
Farine de banane plantain enrichie à $15 \%$ d'anacarde fermentée FB20FCNF $=$ Farine de banane plantain enrichie à 20\% d'anacarde non fermentée $; \mathbf{F B 2 0 F C F}=$ Farine de banane plantain enrichie à $20 \%$ d'anacarde fermentée $; \quad$ BLEDINE = Farine infantile témoin du commerce.

\section{Les composés polyphénoliques et antinutritionnels}

Les résultats du Tableau 3 rendent compte de la composition en composés polyphénoliques et antinutritionnels des différentes farines.

Concernant les polyphénols totaux, La fermentation a une influence sur la teneur en polyphénols des farines d'amande de cajou. Elle passe de 481,39 $\pm 0,95 \mathrm{mgEAG} / 100 \mathrm{~g} \mathrm{MS}$ (FCNF) à 635,32 $\pm 0,00 \mathrm{mgEAG} / 100 \mathrm{~g}$ MS (FCF). Cette même tendance est observée lors de la fortification de la farine de banane. Ces teneurs passent de 320,61 $\pm 0,00 \mathrm{mgEAG} / 100 \mathrm{~g}$ MS (FB) à 559,04 $\pm 0,60 \mathrm{mgEAG} / 100 \mathrm{~g}$ MS à $20 \%$ d'incorporation de farine d'amande de cajou fermentée et à 454,22 $\pm 0,34 \mathrm{mgEAG} / 100 \mathrm{~g}$ MS à $20 \%$ d'incorporation de farine d'amande de cajou non fermentée. Ces teneurs sont supérieures à la teneur en polyphénols de la farine témoin BLEDINE $(173,87 \pm 0,60 \mathrm{mgEAG} / 100 \mathrm{~g} \mathrm{MS})$.

Contrairement à la teneur en polyphénols totaux la fermentation a entrainé une diminution significative des teneurs en tanins et en oxalates dans la farine d'amande de cajou. Ces teneurs passant respectivement de $19,93 \pm 2,22 \mathrm{mgEAG} / 100 \mathrm{~g}$ et $220,00 \pm 0,00 \mathrm{mg} / 100 \mathrm{~g}$ dans la farine non d'amande de cajou non fermentée à respectivement 10,74 $\pm 1,35$ mgEAG / $100 \mathrm{~g}$ et $201,66 \pm 6,35 \mathrm{mg} / 100 \mathrm{~g}$ dans la farine d'amande de cajou fermentée. Ainsi la fermentation de l'amande de cajou entraine une diminution significative de la teneur en tanins et une augmentation moins significative en oxalates lors de la fortification de la farine de banane plantains comparativement à l'incorporation de la farine non fermentée.

Tableau 3 : Teneurs en composés phénoliques et antinutritionnels des farines composites à base de banane plantain et d'amande de cajou

\begin{tabular}{|c|c|c|c|}
\hline Formulations & $\begin{array}{c}\text { Polyphénols totaux } \\
(\mathrm{mgEAG} / 100 \mathrm{gMS})\end{array}$ & $\begin{array}{c}\text { Tanins } \\
(\mathrm{mgEAG} / 100 \mathrm{~g})\end{array}$ & $\begin{array}{c}\text { Oxalates } \\
(\mathrm{mg} / 100 \mathrm{~g})\end{array}$ \\
\hline FB & $320,61 \pm 0,00^{\mathrm{c}}$ & $41,69 \pm 0,19^{\mathrm{b}}$ & $32,00 \pm 0,00^{\mathrm{f}}$ \\
\hline FCNF & $481,39 \pm 0,95^{\text {bd }}$ & $19,93 \pm 2,22^{\mathrm{e}}$ & $220,00 \pm 0,00^{\mathrm{a}}$ \\
\hline FCF & $635,32 \pm 0,00^{\mathrm{a}}$ & $10,74 \pm 1,35^{\mathrm{f}}$ & $201,66 \pm 6,35^{\mathrm{b}}$ \\
\hline FB10FCNF & $353,47 \pm 0,61^{\mathrm{ce}}$ & $40,90 \pm 0,92^{\mathrm{b}}$ & $44,00 \pm 0,00^{\mathrm{e}}$ \\
\hline FB15FCNF & $387,63 \pm 0,60^{\text {cde }}$ & $34,05 \pm 0,00^{\mathrm{c}}$ & $73,33 \pm 12,70^{\mathrm{d}}$ \\
\hline FB20FCNF & $454,22 \pm 0,34^{\text {bde }}$ & $30,86 \pm 1,66^{\mathrm{cd}}$ & $102,66 \pm 6,35^{\mathrm{c}}$ \\
\hline FB10FCF & $388,65 \pm 0,61^{\text {cde }}$ & $34,40 \pm 0,00^{\mathrm{c}}$ & $40,33 \pm 6,35^{\text {ef }}$ \\
\hline FB15FCF & $456,76 \pm 1,12^{\text {bde }}$ & $27,97 \pm 0,00^{\mathrm{d}}$ & $66,00 \pm 0,00^{\mathrm{d}}$ \\
\hline FB20FCF & $559,04 \pm 0,60^{\text {ab }}$ & $23,58 \pm 5,34^{\mathrm{e}}$ & $99,00 \pm 0,00^{\mathrm{c}}$ \\
\hline BLEDINE & $173,87 \pm 0,60^{\mathrm{f}}$ & $69,95 \pm 5,10^{\mathrm{a}}$ & $36,66 \pm 6,35^{\text {ef }}$ \\
\hline
\end{tabular}


Toutes ces valeurs sont les moyennes de trois déterminations. Les notes de la même colonne portant en exposant des lettres différentes sont statistiquement différentes à $\mathrm{P} \leq 0,05$.

$\mathbf{F B}=$ Farine de banane plantain ; $\mathbf{F C N F}=$ Farine d'anacarde non fermentée ; $\mathbf{F C F}=$ Farine d'anacarde fermenté $; \mathbf{F B 1 0 F C N F}=$ Farine de banane plantain enrichie à 10\% d'anacarde non fermentée ; FB10FCF= Farine de banane plantain enrichie à 10\% d'anacarde fermentée; FB15FCNF= Farine de banane plantain enrichie à 15\% d'anacarde non fermentée ; FB15FCF= Farine de banane plantain enrichie à $15 \%$ d'anacarde fermentée $\mathbf{F B 2 0 F C N F}=$ Farine de banane plantain enrichie à $20 \%$ d'anacarde non fermentée ; FB20FCF $=$ Farine de banane plantain enrichie à 20\% d'anacarde fermentée ; BLEDINE = Farine infantile témoin du commerce

\section{Analyse sensorielle}

L'acceptabilité globale des bouillies présentée dans le tableau 4, montre que les bouillies ont été diversement appréciées. Les résultats montrent que la fermentation de $72 \mathrm{~h}$ entraine une diminution de l'acceptabilité globale des bouillies proportionnellement au taux d'incorporation de la farine d'amande cajou. Les bouillies de farine de plantain additionnées de 15\% d'anacarde non fermentée (note de 7,07) et de $10 \%$ d'anacarde fermentée (note de 6,98) sont les plus appréciées dans les deux lots de formulations. Toutes les bouillies enrichies avec la farine d'amande de cajou non fermentée sont plus appréciées que la bouillie de banane plantain non fortifiée. Les résultats des tests descriptifs montrent que les critères sensoriels qui ont influencé l'acceptabilité des bouillies lors de la fermentation sont l'arôme, la couleur et la texture. La fermentation a entrainé une diminution proportionnellement au taux d'incorporation de la farine d'amande de cajou l'acceptabilité des bouillies au niveau de la couleur, de l'arôme et du goût. Toutefois l'acceptabilité au niveau de la texture (viscosité, aspect crémeux et lisse) est plus accrue dans les bouillies fermentées.

Tableau 4 : Caractéristiques sensorielles des bouillies à base de banane plantain et d'amande de cajou

\begin{tabular}{|c|c|c|c|c|c|c|c|}
\hline \multicolumn{8}{|c|}{ Paramètres } \\
\hline $\begin{array}{l}\text { Formulati } \\
\text { ons }\end{array}$ & Couleur & $\begin{array}{c}\text { Saveur } \\
\text { agréable }\end{array}$ & $\begin{array}{c}\text { Odeur } \\
\text { Banane }\end{array}$ & $\begin{array}{c}\text { Texture } \\
\text { lisse }\end{array}$ & $\begin{array}{c}\text { Aspect } \\
\text { Visqueu } \\
\text { X }\end{array}$ & $\begin{array}{l}\text { Aspect } \\
\text { crémeux }\end{array}$ & $\begin{array}{l}\text { Appréciat } \\
\text { ion } \\
\text { générale }\end{array}$ \\
\hline FB & $\begin{array}{c}6,15 \pm 0 \\
47^{\mathrm{e}}\end{array}$ & $\begin{array}{c}7,18 \pm 1 \\
01^{\mathrm{b}}\end{array}$ & $\begin{array}{c}8,18 \pm 1, \\
91^{\mathrm{a}}\end{array}$ & $\begin{array}{c}7,31 \pm 0, \\
73^{\mathrm{c}}\end{array}$ & $\begin{array}{c}7,77 \pm 0,9 \\
7^{\mathrm{a}}\end{array}$ & $\begin{array}{c}4,75 \pm 2,4 \\
3^{\mathrm{f}}\end{array}$ & $\underset{f}{6,10 \pm 1,21}$ \\
\hline $\begin{array}{c}\text { FB10FCN } \\
\text { F }\end{array}$ & $\begin{array}{c}7,18 \pm 2 \\
46^{\mathrm{d}}\end{array}$ & $\begin{array}{c}6,15 \pm 1 \\
45^{\mathrm{f}}\end{array}$ & $\begin{array}{c}7,87 \pm 1, \\
26^{\mathrm{b}}\end{array}$ & $\begin{array}{c}6,32 \pm 1, \\
07^{\mathrm{h}}\end{array}$ & $\begin{array}{c}7,21 \pm 0,9 \\
9^{\mathrm{bc}}\end{array}$ & $\begin{array}{c}6,57 \pm 1,8 \\
8^{\mathrm{d}}\end{array}$ & $\begin{array}{c}6,54 \pm 1,21 \\
f\end{array}$ \\
\hline $\begin{array}{c}\text { FB15FCN } \\
\text { F } \\
\end{array}$ & $\begin{array}{c}7,64 \pm 2 \\
35^{\mathrm{b}}\end{array}$ & $\begin{array}{c}6,89 \pm 1 \\
46^{c} \\
\end{array}$ & $\begin{array}{c}6,15 \pm 1, \\
62^{\mathrm{e}}\end{array}$ & $\begin{array}{c}6,47 \pm 1, \\
88^{\mathrm{g}}\end{array}$ & $\begin{array}{c}6,83 \pm 1,5 \\
0^{c} \\
\end{array}$ & $\begin{array}{c}6,69 \pm 1,0 \\
4^{\mathrm{d}} \\
\end{array}$ & $\begin{array}{c}7,07 \pm 1,51 \\
\text { b }\end{array}$ \\
\hline
\end{tabular}




\begin{tabular}{|c|c|c|c|c|c|c|c|}
\hline FB20FCN & $7,34 \pm 1$, & $6,53 \pm 1$, & $5,11 \pm 1$, & $6,76 \pm 0$, & $6,20 \pm 2,2$ & $6,76 \pm 2,4$ & $6,67 \pm 1,52$ \\
$F^{2}$ & $38^{\mathrm{c}}$ & $62^{\mathrm{e}}$ & $34^{\mathrm{d}}$ & $96^{\mathrm{e}}$ & $9^{\mathrm{d}}$ & $4^{\mathrm{cd}}$ & $c^{\mathrm{c}}$ \\
\hline FB10FCF & $6,27 \pm 1$, & $6,76 \pm 1$, & $6,54 \pm 0$, & $7,02 \pm 1$, & $7,32 \pm 0,0$ & $6,62 \pm 1,2$ & $6,98 \pm 1,46$ \\
& $44^{\mathrm{e}}$ & $27^{\mathrm{d}}$ & $05^{\mathrm{d}}$ & $44^{\mathrm{d}}$ & $5^{\mathrm{b}}$ & $5^{\mathrm{d}}$ & $\mathrm{e}^{\mathrm{e}}$ \\
\hline FB15FCF & $5,36 \pm 1$, & $5,48 \pm 1$, & $4,52 \pm 0$, & $6,36 \pm 0$, & $5,84 \pm 0,0$ & $6,90 \pm 1,3$ & $6,21 \pm 1,27$ \\
& $32^{\mathrm{f}}$ & $12^{\mathrm{g}}$ & $05^{\mathrm{g}}$ & $67^{\mathrm{h}}$ & $5^{\mathrm{de}}$ & $1^{\mathrm{bc}}$ & $\mathrm{f}^{\mathrm{b}}$ \\
\hline FB20FCF & $4,72 \pm 1$, & $5,28 \pm 0$, & $3,51 \pm 0$, & $6,63 \pm 0$, & $5,40 \pm 0,0$ & $7,09 \pm 0,9$ & $5,78 \pm 0,89$ \\
& $05^{\mathrm{g}}$ & $85^{\mathrm{h}}$ & $05^{\mathrm{h}}$ & $52^{\mathrm{f}}$ & $5^{\mathrm{e}}$ & $7^{\mathrm{b}}$ & $\mathrm{g}$ \\
\hline BLEDIN & $7,83 \pm 0$, & $8,18 \pm 1$, & $7,28 \pm 0$, & $8,71 \pm 1$, & $4,86 \pm 1,3$ & $7,89 \pm 1,1$ & $7,36 \pm 1,52$ \\
E & $65^{\mathrm{a}}$ & $34^{\mathrm{a}}$ & $34^{\mathrm{c}}$ & $27^{\mathrm{a}}$ & $0^{\mathrm{f}}$ & $1^{\mathrm{a}}$ & ${ }^{\mathrm{a}}$ \\
\hline FARINO & $7,11 \pm 0$, & $4,36 \pm 0$, & $1,00 \pm 0$, & $7,90 \pm 1$, & $4,90 \pm 1,2$ & $6,07 \pm 1,2$ & $4,28 \pm 1,78$ \\
R & $64^{\mathrm{d}}$ & $34^{\mathrm{a}}$ & $00^{\mathrm{i}}$ & $36^{\mathrm{b}}$ & $1^{\mathrm{f}}$ & $1^{\mathrm{e}}$ & $\mathrm{d}$ \\
\hline
\end{tabular}

Les notes de la même colonne portant en exposant des lettres différentes sont statistiquement différentes à $\mathrm{P} \leq 0,05$.

$\mathbf{F B}=$ Farine de banane plantain $; \mathbf{F C N F}=$ Farine d'anacarde non fermentée ; $\mathbf{F C F}=$ Farine d'anacarde fermenté $; \mathbf{F B 1 0 F C N F}=$ Farine de banane plantain enrichie à $10 \%$ d'anacarde non fermentée $\mathbf{F B 1 0 F C F}=$ Farine de banane plantain enrichie à 10\% d'anacarde fermentée ; FB15FCNF $=$ Farine de banane plantain enrichie à $15 \%$ d'anacarde non fermentée ; FB15FCF= Farine de banane plantain enrichie à $15 \%$ d'anacarde fermentée FB20FCNF $=$ Farine de banane plantain enrichie à 20\% d'anacarde non fermentée ; FB20FCF $=$ Farine de banane plantain enrichie à $20 \%$ d'anacarde fermentée $;$ BLEDINE et FARINOR = Farines infantiles témoins du commerce

\section{Discussion}

L'augmentation de la teneur en protéines des mélanges pourrait être attribuée à des teneurs élevées en protéine dans la farine d'amande de cajou déshuilée (Emelike et al., 2015). Cette constatation a été faite lors d'une autre étude dans laquelle la farine de cajou a été utilisée dans la fortification $\mathrm{du}$ popcorn à base de maïs (Ijarotimi et al, 2012).L'augmentation significative $(\mathrm{P}<0,05)$ de la teneur en protéines des échantillons fermentés est en accord avec des travaux antérieurs qui ont démontré une augmentation des niveaux de protéines chez amahewu produits en présence de levure (Chelule et al., 2010). Azoulay., 1978 a également signalé une augmentation de 15 à $30 \%$ de la teneur en protéines en raison de la fermentation du maïs, avec une levure appropriée telle que Candida tropicalis. L'augmentation de la teneur en protéines après la fermentation serait attribuable à une diminution du taux de carbone dans la masse totale (Onyango et al., 2004). Les microorganismes utilisent les glucides comme source d'énergie et produisent du dioxyde de carbone comme sous-produit. Cela entraîne la concentration de l'azote dans les farines fermentées, et ainsi, la proportion de protéines dans la masse totale augmente. 
L'augmentation de la teneur en lipides pendant la période de fermentation est comparable aux travaux d'Oyarekua., 2013. L'augmentation peut être probablement due à l'augmentation des activités des lipases qui hydrolysent les graisses en glycérol et acides gras (Odunfa., 1983). Les acides gras peuvent avoir été utilisés pour la synthèse de nouveaux lipides. L'augmentation de la teneur en matières grasses favoriserait l'absorption des minéraux et vitamines liposolubles (Ribaya-Mercado, 2004). Toutefois, malgré cette augmentation les teneurs en lipides de l'ensemble sont restées inférieures au niveau de graisse recommandée de $10-25 \%$ pour les aliments de sevrage (FAO/WHO, 1991). Aussi, cette faible teneur en matières grasses pourrait contribuer à l'augmentation de la durée de - vie des formulations en diminuant les chances de rancissement.

Les calories dans le régime alimentaire du nourrisson sont produites par des protéines, lipides et glucides. L'augmentation de la matière grasse augmenterait la densité énergétique des farines. Compte tenu de la petite taille de leur estomac (30 à $40 \mathrm{~g} / \mathrm{kg}$ de poids corporel soit 150 à $200 \mathrm{ml}$ ), Brown et al., 1998 ont recommandé que les aliments donnés aux nourrissons et aux enfants soient denses en énergie car les aliments à faible énergie ont tendance à limiter l'apport énergétique total et l'utilisation d'autres nutriments. Cela implique que la fermentation serait un moyen efficace d'augmentation de la valeur énergétique des fortifications à base d'amande de cajou.

La fermentation a diminué le niveau de glucides des farines (Soro et al., 2013, et Nnam Obiakor., 2003). La baisse est probablement attribuable à l'utilisation de l'élément nutritif en particulier de son métabolite, le sucre simple, comme une source d'énergie (Achinewhu., 1986), et l'utilisation de l'hydrate de carbone pour fournir le squelette de carbone pour la synthèse d'autres composés (Kazanas et champs., 1981). Il est connu que les enzymes amylolytiques hydrolysent l'amidon et oligosaccharides en sucres simples solubles libres pendant la fermentation. Les activités des enzymes amylolytiques pour décomposer les glucides complexes en sucres simples et plus absorbables sont susceptibles d'augmenter la disponibilité des éléments nutritifs dans les échantillons fermentés (Nnam et Obiakor., 2003).

$\mathrm{La}$ diminution des teneurs en fibres au cours de la fermentation pourrait être attribué à la production par les microorganismes d'enzymes (cellulases et hemicellulases) de dégradation de la cellulose/ hémicellulose (Lateef et al., 2008 et Moore et al., 2007). Toutefois, Il est recommandé un faible niveau de la teneur en fibres dans les aliments complémentaires (Olorunfemi et al, 2006), et que la faible teneur en fibres dans l'alimentation complémentaire réduit l'encombrement de la nourriture et encourage une haute digestibilité et l'absorption des nutriments tels que les protéines et les minéraux. Les teneurs en fibres des mélanges étaient 
conforme à la valeur $(\leq 5 \mathrm{~g} / 100 \mathrm{~g})$ recommandée (FAO/WHO., 1991) ce qui permettrait aux enfants de consommer la plupart des échantillons alimentaires afin de répondre à leur énergie quotidienne et à d'autres exigences nutritives essentielles (Eka et al., 1971).

L'augmentation significative de la teneur en cendre de la farine de banane plantain suite à la fortification est attribuable à la forte teneur en cendre de la farine d'amande de cajou déclarée (Aremu et al, 2006 et Omusuli et al, 2009). Toutefois, la diminution de la teneur en cendre dans la farine d'amande de cajou suite à la fermentation pourrait être due à la perte dans le milieu de fermentation de certains minéraux hydrosolubles et aux différents traitements thermiques notamment la cuisson des amandes. Toutefois, la teneur en cendre des différentes formulations est comprise entre 1,5\% - 2,5\% recommandées (Pomeranz, et Clifton., 1981). Ainsi, l'incorporation de la farine d'amandes de cajou non fermentées ou fermentées pourrait augmenter la teneur en minéraux, car le taux de cendre est indicatif de la teneur globale en minéraux contenus dans les produits alimentaires.

La production d'acides organiques suite au métabolisme des microorganismes présents au cours de la fermentation justifierait la baisse du $\mathrm{pH}$ des farines enrichies à la farine d'amande de cajou fermentée (Caplice et Fitzgerald, 1999). Ainsi grâce à l'acidification des farines, la fermentation permettrait de limiter le développement de micro-organismes pathogènes et/ou de dégradation (Caplice et Fitzgerald, 1999).

Le gonflement de la farine indique le degré d'absorption d'eau des granules d'amidon (Carcea et al., 1997). La capacité à absorber l'eau est liée au caractère hydrophile de l'amidon et donc à sa teneur en amylopectine responsable du réseau amorphe. La diminution significative de la capacité de gonflement des farines suite à la fermentation est comparable aux travaux de formulations de farines infantiles à base d'igname et de soja (Soro et al., 2013). Cela serait imputable à la dégradation de l'amidon de la farine d'anacarde par les amylases en faveur de la fermentation. L'amidon est souvent la principale source d'énergie des aliments traditionnels, mais lorsqu'il est chauffé avec de l'eau, des granules d'amidon gélatinisent pour produire une bouillie épaisse (visqueuse) et volumineuse. Ces aliments complémentaires ont tendance à être de faible densité en énergie et en protéines. Aussi, Akissoe et al., 2003 ont établi une corrélation entre le pouvoir de gonflement des farines et la viscosité des bouillies $(\mathrm{r} 2=0,63)$. Ainsi la fermentation de l'amande de cajou et son incorporation à la farine de banane plantain permettrait de préparer des bouillies plus concentrées en farines et de fluidité adaptée aux enfants.

L'augmentation de la teneur en polyphénols totaux trouvée dans les échantillons fermentés pourrait être due à la libération des composés 
phénoliques liés pendant la fermentation (Sosulski et al., 1982 ; Bartolome et Gomez-Cordoves, 1999). Une tendance similaire a été observée lors du processus de fermentation de quatre céréales, à savoir le sarrasin, le germe de blé, l'orge et le seigle (Dordevic et al., 2010). Les composés phénoliques ont des propriétés contre le stress oxydant, contre les radicaux libres et contre le vieillissement cellulaire. Ainsi, de par leurs teneurs élevées en polyphénols totaux, les farines formulées pourraient être bénéfiques pour lutter à la fois contre la malnutrition et contre les maladies nutritionnelles (cancer, obésité, diabète de type I) (Yang et al, 2006).

La diminution de la teneur en tanin au cours de la fermentation est conforme aux travaux d'Ijarotimi et al, 2012 lors de l'enrichissement de la farine de popcorn à base de maïs à la farine d'amande de cajou. La diminution en tanin peut être due à l'hydrolyse du composé polyphénolique en des substances plus simples par l'enzyme polyphénol oxydase ou de la décomposition des complexes tanniques (tannin-protéines, les complexes acide-amidon et de tanin-fer tanniques) pour libérer les nutriments libres (Obizoba et Atti., 1991). Ils sont ainsi lessivés dans le milieu de fermentation. Les tanins sont connus pour réduire la disponibilité des protéines, des glucides et des minéraux en formant des complexes non digestibles avec les nutriments. Le niveau de tanin réduit en raison de la fermentation pourrait améliorer la disponibilité des nutriments dans les farines (Nnam et Obiakor., 2003).

Les teneurs en oxalate des farines d'amandes de cajou (fermentée et non fermentée) sont inférieures au taux de $318,4 \mathrm{mg} / 100 \mathrm{~g}$ trouvé dans l'amande (Rebecca et Ian., 2004). L'acide oxalique forme des complexes insolubles avec les cations bivalents (fer, calcium, zinc, et magnésium) ce qui limite la biodisponibilité de ces minéraux pouvant entraîner des carences (Omoruyi et al., 2007). La diminution de la teneur en oxalates dans la farine fermentée pourrait être due en grande partie par la cuisson des amandes avant fermentation (Soudy et al., 2008). En outre, les enfants n'étant pas en mesure de consommer la quantité de bouillie de sevrage leur apportant la dose létale de 5 à $15 \mathrm{~g}$ d'oxalates, l'oxalate des farines formulées ne pourrait pas endommager leur santé.

La qualité organoleptique des bouillies constitue aussi un facteur important dans l'appréciation de la qualité marchande des farines. La diminution de l'appréciation générale des bouillies suite à la fermentation est contraire à celle de Soro et al., 2013 et achi, 1999 qui présentent la fermentation comme un moyen traditionnel d'amélioration de la qualité nutritionnelle et organoleptique des aliments infantiles et ceux destinés aux adultes. Toutefois cette diminution de l'acceptabilité des bouillies pourrait être attribuable à la durée de fermentation $(72 \mathrm{~h})$ à l'origine de la forte coloration des farines et du fort développement de nouvelles odeur et de 
saveur non appréciées des panelistes. Ainsi afin d'accroitre l'acceptabilité des bouillies il serait souhaitable de réduire la durée de fermentation à $48 \mathrm{~h}$ conformément aux travaux de Soro et al., 2013.

\section{Conclusion}

Cette étude a montré que le processus de fermentation de l'amande cajou augmente significativement la valeur nutritive de la farine de banane plantain, notamment en protéines, en lipides, en énergie et en polyphénols totaux. Aussi, a t-elle également conduit à une réduction de la viscosité qui pourrait conférer une plus grande densité d'énergie et de nutriments aux bouillies. Concernant la concentration en antinutriments, la diminution significative des teneurs en oxalates et en tanins pendant la fermentation pourrait affecter positivement la qualité nutritionnelle des farines. Ainsi, la fermentation pourrait être considérée comme un moyen fiable pour améliorer la qualité et la quantité des protéines des formulations contenant la farine d'amande de cajou afin de prévenir les cas de malnutrition par carences. Les tests sensoriels des bouillies ont permis de limiter le taux maximum d'incorporation de la farine d'amande de cajou non fermentée à $15 \%$ et à 10 $\%$ pour la farine d'amande de cajou fermentée. Toutefois, d'autres recherches, telles que l'ajout de légumes locaux disponibles, riches en vitamines et minéraux et des tests biologiques, sont nécessaires pour justifier l'adéquation des formulations en tant que complément alimentaire pour nourrissons.

\section{References:}

1. Abdel-Haleem, W.H., El Tinay, A.H., Mustafa, A.I., Babiker, E.E., 2008. Effect of fermentation, malt-pretreatment and cooking on antinutritional factors and protein digestibility of sorghum cultivars. Pakistan J. Nutr. 7, 335-341.

2. Achi O K. (1999). Quality attributes of fermented yam flour supplemented with processed soy flour. Plant food for Human Nutrition 54: 151-158.

3. Achinewhu SC (1986). Some biochemical and nutritional changes during the fermentation of fluted pumpkin (Telferia occidendtialis). Qualitas Plantarum: Plant Food Hum. Nutr., 36: 97-106.

4. Akinhanmi TF and VN Atasie (2008). Chemical Composition and Physicochemical Properties of Cashew nut (Anacardiumoccidentale) Oil and Cashew nut Shell Liquid J. Agric. Food Environ 2(1): 1-10

5. Akissoe N, Hounhouigan J, Mestres C and M Nago. 2003. How blanching and drying affect the colour and functional characteristics of yam (Dioscorea cayenensis-rotundata) flours. Foods chem. 82 : 257-264. 
6. Ali, A.M., El-Tinay, H.A., Abdalla, H.A., 2003. Effect of fermentation on the in vitro digestibility of pear millet. Food Chem. $80,51-54$.

7. AOAC, 1995. Official Methods for Analysis, 16th ed. Association of Official Analytical Chemists, Arlington VA, USA.

8. Aremu, M. O., Olonisakin, A., Bako, D. A., Madu, P. C., 2006. Compositional studies and physicochemical characteristics of cashew nut (Anacardium occidentale) flour. Pakistan journal of Nutrition 5(4): 328-333.

9. Azoulay, E.E.Y. (1978). Protein enrichment of maize, cassava and other starch products by direct fermentation. United-States-Patent. Patent, USA; Protein-Products

10. Ba K., Tine E., Destain J., Cissé N., Thonart P. Etude comparative des composés polyphénoliques, du pouvoir antioxydant de différentes variétés de sorgho sénégalais et des enzymes amylolytiques de leur malt. Biotecnology,Agronomy, Social and envioronmental Sciences, vol. 14, pp. 131-139, 2010.

11. Bartolome, B. \& Gomez-Cordoves, C. (1999). rley spent grain: release of hydroxycinnamic acids (ferulic and p-coumaric acids) by commercial enzyme preparations. Journal of the Science of Food and Agriculture, 79, 435-439.

12. Bonnet-Bruno C. (2012). Valorisation de la banana Cavendish FWI pour l'obtention de molécules d'intérêts biologiques. Thèse pour doctorat en sciences de la vie. Université des Antilles et de la Guyane, $186 \mathrm{p}$.

13. Brown K. H., Dewey K. G and Allen, L. H. (1998). Complementary feeding of young children in developing countries: a review of current scientific knowledge. WHO, Geneva.

14. Caplice E., Fitzgerald G.F., 1999. Food fermentations: role of microorganisms in food production and preservation. International Journal of Food Microbiology 50, 131-149.

15. Carcea, M., Acquistucci, R. 1997. Isolation and physicochemical characterization of Fonio (Digitaria exillis Stapf). starch. Starch, 49: 131-135.

16. CCA. (2016). Conseil du coton et de l'anacarde en Côte d'Ivoire). Publié le lundi 15 février.

17. Chelule, P.K., Mbongwa, H.P., Carries, S. \& Gqaleni, N. (2010). Lactic acid fermentation improves the quality of amahewu, a traditional South African maize-based porridge. Food Chemistry, $122,656-661$. 
18. Corke H and J Li. (1999). Physicochemical properties of normal and low-amylose job's Tears (Coix lachryma-job L.). Starch cereal chem 76(3): 413-416.

19. Day RA and AL Underwood, 1986 Qualitative Analysis, 5th Ed. Prentice-Hall Publications, New Delhi, India, p.701.de Lumen, B.O., Becker, R., Reyes, P.S., 1986. Legumes and a cereal with high methionine/cystine contents. Journal of Agric. Food Chem. 34:361364.

20. Dordevic, T.M., Siler-Marinkovic , S.S. \& Dimitrijevic'-Brankovic' , S.I. (2010). Effect of fermentation on antioxidant properties of some cereals and pseudo cereals. Food Chemistry, 119, 957-963.

21. Ejigui, J., Savoie, L., Marin, J., Desrosiers, T., 2005. Beneficial changes and drawbacks of a traditional fermentation process on chemical composition and antinutritional factors of yellow Maize (Zea mays). J. Biol. Sci. 5 (5), 590-596.

22. Eka, O. U and Edijala J.K. (1972). Chemical composition of some traditionally prepared Nigerian foods. Nigerian Journal of Science 6: 157-162.

23. EL Hag, M.E., El Tinay, A.H., Yousif, N.E., 2002. Effect of fermentation and dehulling on starch, total polyphenols, phytic acid and in vitro digestibility of pearl millet. Food Chem. 77, 193-196.

24. Eltayeb, M.M., Hassan, A.B., Sulieman, M.A., Babiker, E.E., 2007. Effect of processing followed by fermentation on antinutritional factors content of pearl millet (Pennisetum glaucum L.) cultivars. Pakistan. J. Nutr. 6, 463-467.

25. Emelike N.J. T., Barber L.I., Ebere C. O. (2015). proximate, mineral and functional properties of defatted and undefatted cashew (anacardium occidentale linn.) kernel .European Journal of Food Science and Technology 3(4): pp.11-20

26. FAO/WHO. (1991). Guidelines on Formulated Supplementary Foods for Older Infants and Young Children. Codex Alimentarius (CODEX CAC/GL 08): 4: FAO/WHO Joint Publications.

27. Fardiaz D, Markakis P (1981). Degradation of phytic acid in oncom (fermented peanut press cake). J. Fd Sci., 46: 523-525.

28. Ijarotimi OS, Oluwalana IB and MO Ogunedojutimi, 2012. Nutrient composition, functional, sensory and microbial status of popcornbased (zea may everta) complementary foods enriched with cashew nut (anacardiumoccidentale l.) flour. African Journal of Food Science 12(5) : 6424-6446

29. Inyang, C.U., Zakari, U.M., 2008. Effect of germination and fermentation of pearl millet on proximate, chemical and sensory 
properties of instant "Fura-Nigerian cereal food. Pakistan J. Nutr.7, 9-12.

30. Kazanas N, Fields ML (1981). Nutritional improvement of sorghum by fermentation. J. Fd Sci., 49: 819-821.

31. Lateef A., Oloke J.K., Gueguim Kana E.B., OyeniyiS.O., Onifade O.R., Oyeleye A.O., Oladosu O.C. and Oyelami A.O., 2008. Improving the quality of agro-wastes by solid-statefermentation: Enhanced antioxidant activities and nutritional qualities. World J. Microbial.Biotechnol. 24 : 2369-2374.

32. Mbugua, S.K. (1988). The nutritional and fermentation characteristics of uji produced from dry milled flour (unyabaridi) and whole wet milled maize. Chem. Mikrobiol Technol Lebensm, 10, 154-161.

33. Meilgaard, Civille GV and BT Carr. (1999). Sensory Evaluation Techniques. 3rd Edn., CRC Press, New York.

34. Moore J., Cheng Z., Hao J., Guo G., Guo-Liu J., Lin C. and Yu L. (Lucy), 2007. Effects of solid-state yeast treatment on the antioxidant properties and protein and fiber compositions of common hard wheat bran. J. Agric. Food Chem. 55: 10173-10182.

35. Nascimento, A. N., Naozuka, J., \& Oliveira, P. V. (2010). In vitro evaluation of $\mathrm{Cu}$ and $\mathrm{Fe}$ bioavailability in cashew nuts by off-line coupled SEC-UV and SIMAAS. Microchemical Journal 96: 58-63.

36. Nnam NM, Obiakor PN (2003). Effect of fermentation on the nutrient and antinutrient composition of baobab (Adansonia digitata) seeds and rice (Oryza sativa) grains. Ecol. Food Nutr., 42: 265-277.

37. Obizoba IC, Atti JV (1991). Effect of soaking, sprouting, fermentation and cooking on nutrient composition and some antinutritional factors of sorghum (guinesia) seeds. Plant Foods Hum. Nutr., 41: 203-212.

38. Odunfa SA (1983). Biochemical changes during production of ogiri, a fermented melon (Citrus vulgaris Schard) product. Qualitas Plantarum: Plant Foods Hum. Nutr., 32: 45-52

39. Olorunfemi, O.B., Akinyosoye, F. A and Adetuyi, F. C. (2006). Microbial and nutritional evaluation of infant weaning food from mixture of fermented food substrates. Research Journal of Biological Science, 1: 20-23.

40. Omosuli S.V., Ibrahim T.A., Oloye D., 2009. Proximate and mineral composition of roasted and defatted cashew nut flour. Patistan Journal of Nutrition, 8(10), 1649 - 1651.

41. Onyango, C., Noetzold, H., Bley, T. \& Henle, T. (2004). Proximate composition and digestibility of fermented and extruded uji from maize-finger millet blend. Lebensm.-Wiss. u.-Technol, 37, 827-832. 
42. Osman, M.A., 2004. Changes, in sorghum enzyme inhibitors, phytic acid, tannins, and in vitro protein digestibility occurring during Khamir (local bread) fermentation. Food Chem. 88, 129-134.

43. Oyarekua MA, 2013. Effect of co-fermentation on nutritive quality and pasting properties of maize/cowpea/sweet potato as complementary food. African Journal of Food Science, 13(1) : 71717191

44. Pérez-Sira E. (1997). Characterization of starch isolated from plantain (Musa paradisiaca normalis). Starch/Stärke 49: 45-49.

45. Pomeranz, Clifton, D. 1981. Properties of defatted soybean, peanut, field pea and pecan flours. In food analysis theory and practices. Westport, L.T, AVI Publishing Comp. P.17 J. Food Sci., 42: 14401450.

46. Ribaya-Mercado JD, 2002 Influence of dietary fat on $\beta$-carotene absorption and bioconversion into vitamin A. Nutr. Rev., 60: 104110.

47. Soro S, Konan G, Elleingand E, N'guessan D and E Koffi. (2013). Formulation d'aliments infantiles à base de farines d'igname enrichies au soja. African Journal of Food agriculture nutrition and development. 3(5):8313-8339.

48. Sosulski, F., Krygier, K. \& Hogge, L. (1982). Free, esterified, and insoluble-bound phenolic acids. Composition of phenolic acids in cereal and potato flours. Journal of Agriculture and Food Chemistry, 30: 330-340.

49. Sze-Tao KWC and SK Sathe.(2004). Functional properties and invitro digestibility of Almond (Prunus dulcis L) protein isolate. Food chemistry 69: 153- 160.

50. Yang R.Y. \& Tsou S.C.S. (2006). Enhancing iron bioavailability of vegetables through proper preparation principles and applications. Journal of International Cooperation. 1: 107-119.

51. Yang, J. (2009). Brazil nuts and associated health benefits: a review. Lebensmittel Wissenschaft und Technologie, 42, 1573-1580. 